\title{
Typeface "Garuda Batik" sebagai Duta Budaya Indonesia
}

\author{
Natalia Hasti Lumenta
}

Staff Pengajar Program Studi Desain Komunikasi Visual ASRD Modern School of Design Yogyakarta

Email : hastilumenta@gmail.com

\begin{abstract}
The discovery of artifacts writings on various historical relics prove that typography has accompanied the development of human civilization and be a liaison between the times. Naturally, if the typography is referred to as a reliable means of communication because it is able to survive for centuries in establishing universal human interaction. The emergence of thousands of fonts and "experimental typography " on various types of media indicate that the function of typography as the expanding literacy has become the object of an experimental and artistic expression. Discretion of the function used to create a typeface that represents local knowledge of Javanese culture that was adapted from the classic batik motifs Garuda Yogyakarta style of the interior. Value mythical eagle valuable and unique artistic value of scratches batik canting an inspiration in the creation of the typeface Garuda Batik. The figure of the eagle that had accompanied the history of the Indonesian nation is at once the spirit of the nation's cultural heritage that should be preserved. Universal nature of typography is the right solution to communicate the values contained in the motif of Garuda in the global arena. Typeface Garuda Batik able to adapt to the lifestyle of modern society through its applications in various types of media, techniques, and visual styles are up to date. Typeface Batik Garuda is also a tangible manifestation of nationalism human visual communication design to create a national paradigm design work..
\end{abstract}

Keyword :typeface, Garuda Batik, the design of national paradigm

\section{PENDAHULUAN}

Krisis identitas budaya merupakan permasalahan besar yang menyangkut kewibawaan suatu bangsa. Klaim atas asetaset budaya Indonesia yang dilakukan oleh negara lain mengindikasikan adanya kegamangan spirit kebangsaan pada sendisendi kehidupan bangsa ini. Krisis nasionalisme yang menggerogoti bangsa ini menuntut hadirnya simbol-simbol spirit bangsa di kehidupan sehari-hari, maka publikasi melalui dunia maya harus disertai dengan media-media lain yang menjangkau berbagai aspek kehidupan masyarakat.Dinamisasi dalam desain komunikasi visual yang menyertai perkembangan teknologi dapat dijadikan sebagai peluang terciptanya berbagai solusi.Isu nasionalisme pada umumnya digarap melalui Iklan Layanan Masyarakat yang pesannya dapat didistribusikan 
melalui berbagai jenis media.Namun efektifitas ILM cenderung sulit bersaing dengan maraknya pesan-pesan komersial yang performanya lebih ekspresif dan sensasional.Salah satu elemen dalam desain komunikasi visual yang saat ini berpeluang untuk dieksplor sebagai pemikat perhatian khalayak adalah tipografi.Penciptaan typeface dapat difungsikan sebagai representasi suatu pesan yang pada prinsipnya dimanapun typeface ini muncul secara tak langsung telah membawa misi kampanye kebangsaan.

Tipografi secara klasik didefinisikan sebagai ilmu, penggunaan, dan penataan komposisi dari huruf-huruf. Tipografi mampu menjadi daya tarik tersendiri karena sifatnya yang dapat dipahami, dimaknai bahkan dinikmati secara universal serta dapat bertahan untuk jangka waktu yang tak terbatas, seperti dikatakan oleh Sihombing (2009: 66) bahwa:

Tipografi adalah irisan antara seni dengan desain.Ia begitu kaya dengan kandungan sifat simbolik dan nilai filosofis yang diimplementasikan ke dalam sisi praktis. Ia memiliki aturan, keterbatasan dan nilai-nilai yang lahir dari tradisi yang terbangun menjadi kekinian.

Evolusi dari bahasa tulis merupakan salah satu bagian dari perjalanan peradaban manusia guna mencapai kemudahan hidup, terutama dalam cara berkomunikasi. Secara garis besar, tahaptahap prinsip dalam perkembangan komunikasi diawali darispeech, pictures, figurative script : the ideograph, phonetic script, an international sign : zero, movable type, telegraph, telephone, gramaphone, radio, television. (Unesco, 1965: 47) Berawal dari sifat naluriah hingga berkembangnya akal manusia dari abad ke abad menjadikan tulisan (huruf) sebagai sebuah hasil karya yang kian sempurna.Manfaat atau jasa terbesar dari tulisan adalah sebagai penghubung antar manusia dalam merepresentasikan isi hati, pikiran, ide, emosi dan apapun yang tak berujud (abstrak) menjadi kasat mata. Lazlo Moholy dalam Kusrianto (2007 : 191) berpendapat bahwa tipografi adalah alat komunikasi. Oleh karena itu, tipografi harus bisa berkomunikasi dalam bentuknya yang paling kuat, jelas(clarity), dan terbaca (legibility).

Namun rupanya tipografi di era digital semakin membebaskan dirinya dari keterikatan fungsi konvensional sebagai alat baca-tulis. Berryman (1979: 22) mengatakan bahwa"Good Typography is a fusion of information and inspiration, of the concious and unconcious, of yesterday and today, of fact and fantasy, work and play, craft and art".Eksplorasi tipografi bukan lagi semata memperkaya varian jenis huruf (font) sebagai akomodasi baca tulis melainkan sebagai representasi gagasan atau emosi yang diekspresikan secara visual. Gejala tersebut muncul sejalan dengan perkembangan berbagai kepentingan dalam aplikasi tipografi yang semakin tak terbatas, baik dari aspek tujuan komunikasi, media, teknologi, atau sekedar ekspresi seni.Munculah suatu gejala yang disebut sebagai experimental typography,yaitu "tipografi yang melalui pendekatan dan terobosan baru atau terobosan dan pendekatan yang tidak 
lazim."(Concept, 2008: 14)

Motif Garuda pada batik klasik menjadi inspirasi dalam penciptaan typeface berkarakter kebangsaan Indonesia. Secara spesifik, eksplorasi visual typeface mengacu pada motif Garuda (gurdha) dari batik klasik pedalaman gaya Yogyakarta. Keunikan detail motif batiknya sangat berpotensi untuk diadaptasi dalam bentuk typeface dekoratif.
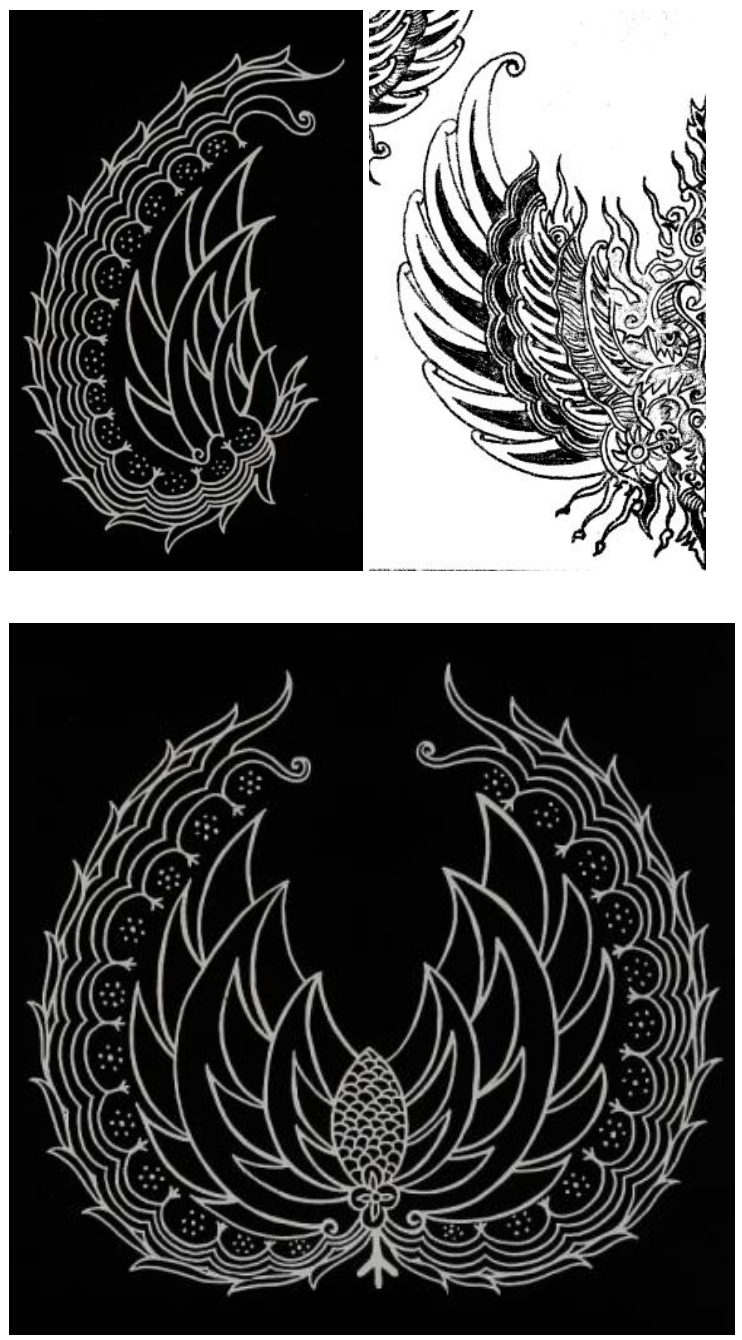

Gambar.2. Beberapa contoh motif garuda dan pengembangannya

Widodo mengutip penjelasan Bronwen\& Solyom dalam Wisetrotomo (2009: 86) bahwa motif Garuda dalam motif Semen Rama diwujudkan dengan bentuk sawat dan lar, yaitu berujud sayap burung garuda, melambangkan sifat tabah. Garuda dijadikan simbol matahari sesuai perannya sebagai lambang dewa tertinggi Kahyangan dan alam semesta. Mitos tersebut memunculkan inspirasi untuk menjadikan sosok Garuda sebagai simbol negara RI seperti dikatakan Aryandini S dalam Hitchcock (2000:105) bahwa :

Garuda was chosen as the symbol of Republic of Indonesia for this succesful effort to free his mother from the suffering of slavery. To the indonesian people, the mother is Pertiwi (meaning motherland), who had been set free by Garuda, her mighty son (the young generation) from slavery and subjugation. Be brave and mighty like eagle who respected his father always (Sang kasyapa) When Indonesians look at the sky, we see our father, Father sky.

\section{LANDASAN PENCIPTAAN}

Terdapat 3 (tiga) hal yang menjadi landasan dalam penciptaan typeface Garuda Batik ini yang masing-masing menjadi acuan dalam mengeksplorasi gagasan empirik sehingga dapat dipertanggungjawabkan secara akademis.

A. Kaidah Batik klasik Garuda

Motif batik garuda termasuk dalam salah satu golongan batik klasik yaitu golongan motif semen yang mana ornamenornamennya lebih bebas digambarkan atau digubah jika dibandingkan dengan golongan motif lainnya. Motif-motif batik klasik pada umumnya mempunyai dua macam keindahan, yaitu :

1. Keindahan visual, yaitu rasa indah yang diperoleh karena perpaduan yang harmoni dari susunan bentuk dan warna melalui pengelihatan atau panca indera. 
2. Keindahan jiwa, atau keindahan filosofis, yaitu rasa indah yang diperoleh karena susunan arti-lambang ornamen-ornamennya yang membuat gambaran sesuai dengan paham yang dimengertinya. (Susanto, 1980: 212)

Di dalam motif batik, ornamen Garuda digambarkan sebagai bentuk stilir dari Burung Garuda, suatu bentuk burung yang perkasa seperti rajawali.(Susanto, 1980: 265). Ornamen Garuda digambarkan dengan beberapa macam bentuk, antara lain :

1. Bentuk dengan dua sayap lengkap dengan ekor terlihat dari sisi depan, disebut "Sawat".

2. Bentuk susunan dua sayap, disebut "Mirong".

3. Bentuk satu sayap, seolah-olah tampak dari samping.

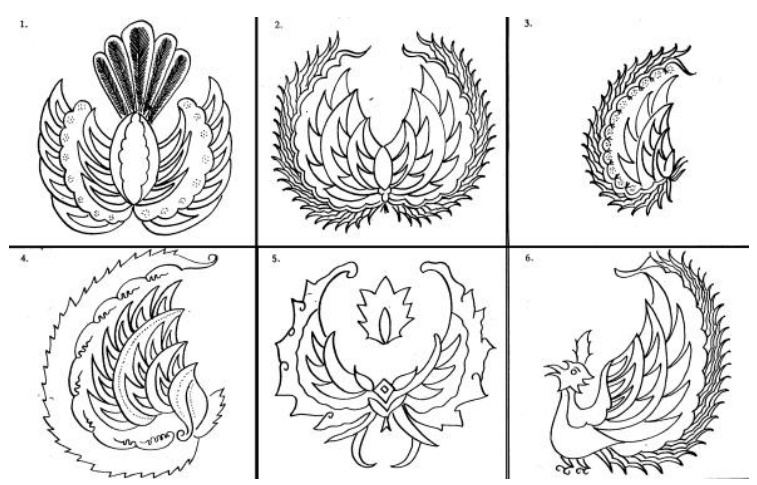

Gambar.2. Contoh motif batik Garuda

\section{B. Semiotika}

Penciptaan typeface Batik Garuda ditunggangi oleh misi komunikasi secara visual. Komunikasi sendiri terjadi dengan perantaraan tanda-tanda, maka landasan penciptaan typeface ini menggunakan pendekatan semiotika, yaitu : "studi tentang tanda dan segala yang berhubungan dengannya; cara berfungsinya, hubungannya dengan tandatanda lain, pengirimannya, dan penerimaannya oleh mereka yang mempergunakannya". (Zoest, 1992: 5)

Pendekatan semiotika yang digunakan mengacu pada pandangan filsuf Amerika yaitu Charles Sanders Pierce (1839-1914). Peirce (Zoest, 1992: 5) mengatakan bahwa makna tanda yang sebenarnya adalah mengemukakan sesuatu. Sedangkan apa yang dikemukakan melalui tanda disebut acuan. Berdasarkan hubungan antara tanda dengan acuan, Peirce membagi tiga hubungan sebagai berikut :

a) hubungan kemiripan antara tanda dengan acuannya, disebut ikon

b) hubungan yang timbul karena ada kedekatan eksistensi, disebut indeks

c) hubungan yang terbentuk secara konvensional, disebut simbol.

Trikotomi Pierce tersebut menjadi pendekatan untuk memaknai tanda-tanda pada typeface Batik Garuda di mana elemen-elemen visualnya secara garis besar dianalisis sebagai ikon dan simbol sebagai berikut :

1. Bentuk huruf $A-Z$

Berdasarkan penggolongan jenis tanda maka tulisan dan huruf merupakan simbol, yang mana tanda tulisan didasarkan pada konvensi, peraturan, atau perjanjian yang disepakati bersama.

2. Gambar figur Garuda

Ketika typeface tersebut menampilkan bentuk Garuda secara utuh maka dapat dimaknai sebagai ikon dari seekor burung yang mirip dengan burung rajawali. Namun figur Garuda sendiri merupakan simbol yang disepakati sejak jaman kemerdekaan sebagai lambang NKRI dengan ciri khas bentuk yang terkonsep 
dan sarat akan makna simbolisnya. Demikian juga ketika typeface hanya menampilkan bentuk sayap sebagai bagian dari burung Garuda, maka dapat dianalisis berdasarkan sudut pandang yang berbeda yaitu a) menurut filosofis batik klasik : sebagai simbol ketabahan berujud sawat dan lar, b) menurut bentuk fisiknya : sebagai ikon dari sayap seekor burung yang tampak perkasa.

3. Gambar motif batik klasik Garuda.

Secara utuh, typeface Batik Garuda merepresentasikan bentuk dan karakter handmade sebagai ikon dari wujud artistik yang khas dari batik tulis bermotif Garuda.Analisis lainnya adalah sebagai simbol dari nilai-nilai filosofis batik Garuda serta nilai kebangsaan yang secara universal telah diyakini oleh masyarakat Indonesia.

Adapun studi semiotika dalam penciptaan ini berpusat pada penggolongan menurut Charles Wiliam Morris yaitu sintaks semiotik, semantik semiotik dan pragmatik semiotik. Ketiganya akan ditelusuri sebagai satu alur kesatuan, namun lebih ditekankan pada semantik semiotik dimana studi ini lebih menonjolkan hubungan tanda-tanda dengan acuannya dan dengan interpretasi yang dihasilkannya.

C. Experimental Typography

Mengacu dari definisi experimental typography menurut Youngky Safanayong (Hutajulu, 2008: 14) yaitu “tipografi yang melalui pendekatan dan terobosan baru atau terobosan dan pendekatan yang tidak lazim." maka penciptaan typeface Batik Garuda menjadi leluasa dalam eksplorasi visual serta aplikasinya pada berbagai wujud atau jenis media. Namun mengingat alternatif aplikasinya yang berfungsi ganda yaitu sebagai ekspresi seni sekaligus kurir komunikasi, maka keleluasaannya masih mempertimbangkan aspek fungsi tipografi sebagai simbol bunyi (ucapan) tertentu. Tulisan sebagai simbol atau kode dalam proses penyampaian pesan dapat dikatakan berfungsi sebagai bahasa komunikasi verbal namun sekaligus visual. Scheder (1994: 21) mengatakan bahwa “adalah penting untuk selalu mengingat bahwa tulisan merupakan bahasa yang nampak.Tulisan tidaklah harus hanya dibaca saja, ia harus ditanggapi dengan perasaan, dengan penghargaan dan cinta".Jelas sekali unsur huruf menjadi suatu tanda yang menghantarkan pada pemaknaan yang lebih jauh dan mendalam dari sekedar alat baca saja. Meskipun kepekaan setiap manusia akan sesuatu makna tidak selalu sama, namun secara alamiah 'sense' yang dimiliki tersebut sudah terbentuk oleh adanya suatu budaya.

Tipografi adalah bagian dari disiplin ilmu desain komunikasi visual yaitu sebagai salah satu elemen visual selain garis, titik, bidang, warna, dan tekstur. Berryman (1979: 22) mengatakan bahwa Good Typography is a fusion of information and inspiration, of the concious and unconcious, of yesterday and today, of fact and fantasy, work and play, craft and art. Keberadaan typeface Batik Garuda tidak sekedar merepresentasikan suatu makna konvensional namun sekaligus mengandung nilai estetika yang melibatkan gagasan, emosi dan ekspresi.Nilai-nilai yang direpresentasikan oleh typeface tersebut mengacu pada kaidah-kaidah dalam batik klasik Garuda. 
Dengan demikian, komposisi ketiga landasan penciptaan dapat diilustrasikan sebagai berikut :

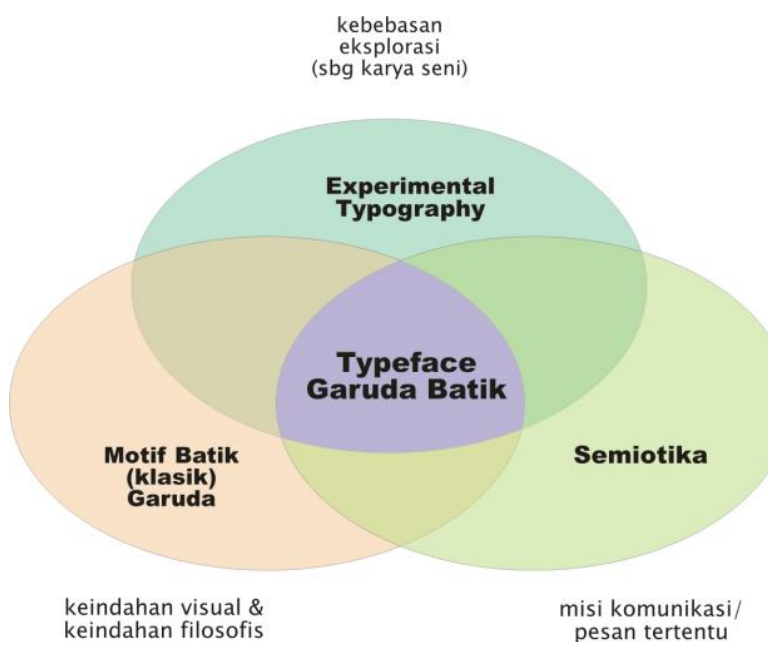

Gambar.3. Contoh motif batik Garuda

\section{EXPLORASI VISUAL}

Tipografi tidak sekedar menghasilkan karya cipta huruf berdasarkan fungsi komunikasi maupun estetisnya.Unsurunsur dalam tipografi sangat kompleks untuk diselami sebagai suatu kajian ilmu.Bahkan di dalamnya melibatkan perhitungan matematis untuk menyajikan tampilan yang ideal di berbagai kepentingan aplikasinya. Penciptaan typeface Garuda Batik terinspirasi dari eksperimental tipografi dengan keleluasaan eksplorasinya, namun proses penciptaannya memperhitungkan hal-hal detail yang mendukung aspek konseptual maupun teknisnya. Ilmu tipografi menjabarkan berbagai aspek penting yang menjadikannya semakin menarik dan unik untuk didalami.

Misi dari perancangan font Garuda Batik adalah untuk menciptakan sebuah typefaceyang merepresentasikan kearifan lokal budaya Jawa yang diadaptasi dari motif Garuda batik klasik gaya pedalaman Yogyakarta. Nilai adiluhung mitos burung garuda serta nilai artistik yang khas dari goresan canting batik menjadi inspirasi dalam penciptaan typeface Garuda Batik.Sosok garuda yang selama ini menyertai perjalanan sejarah bangsa Indonesia merupakan warisan budaya sekaligus semangat bangsa yang patut dilestarikan.

Sifat tipografi yang universal merupakan solusi tepat untuk mengomunikasikan nilai-nilai yang terkandung pada motif Garuda di kancah global.Typeface Garuda Batik mampu beradaptasi dengan gaya hidup masyarakat modern melalui aplikasinya di berbagai jenis media, teknik, maupun gaya visual yang up to date. Typeface Garuda Batik ini juga merupakan wujud nyata sikap nasionalisme insan desain komunikasi visual dengan menciptakan karya desain yang berwawasan kebangsaan.

Secara visual, typefacenya dideformasikan menyerupai stiliran batik tulis motif garuda yang berkarakter handmade. Karakter tersebut merepresentasikan citra klasik dari gaya motif garuda sekaligus proses dari batik tulis khas Indonesia. Eksplorasi visual typefacenya berperan sebagai eyecatcher dalam berbagai aplikasinya pada media.

Penciptaan typeface Garuda Batik mengadaptasi salah satu ciri visual motif batik yang pada umumnya terbentuk dari garis kontur dengan gaya dekoratif. Dekoratif adalah sebuah karya seni yang memiliki daya (unsur) (meng)hias yang tinggi dan dominan. (Susanto, 2002: 30) 
Typeface dekoratif menggunakan teknik sintesis dan deformasi yang mengkombinasikan antara abjad dengan unsur motif garuda.
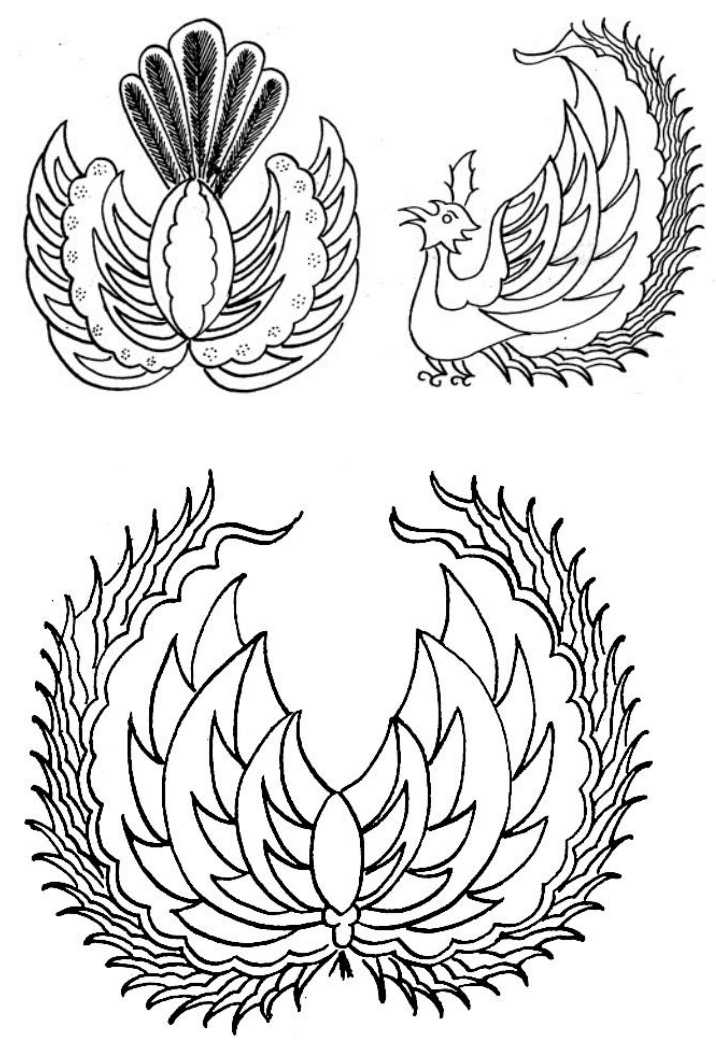

Gambar.4. Motif garuda pada batik. (sumber : Seni Kerajinan Batik Indonesia)

Karakter garis konturnya diadaptasi dari teknik handmade pada batik tulis namun tetap dikombinasikan teknik digital agar terlihat rapi dan legibel sebagai perangkat baca.

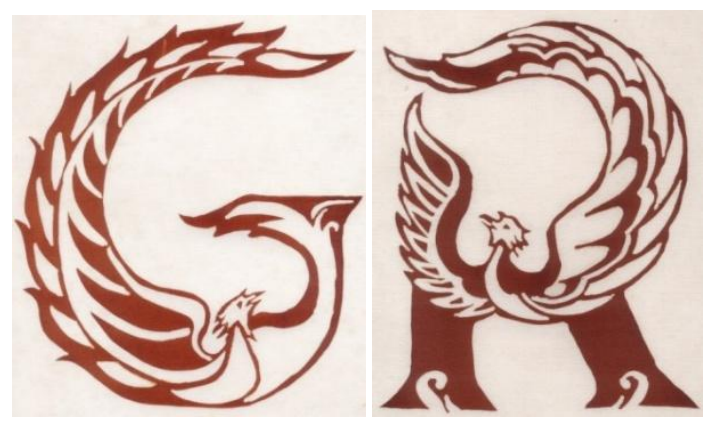

Gambar.5. Beberapa hasil pembuatan typeface dengan batik tulis

Hasil gambar dari batik tulis asli diadaptasikan ke dalam format digital untuk mendapatkan kombinasi dari kedua karakter tersebut. Berikut ini perbandingan antara karakter goresan batik tulis asli, karakter kombinasi handmade -digital, dan karakter digital :

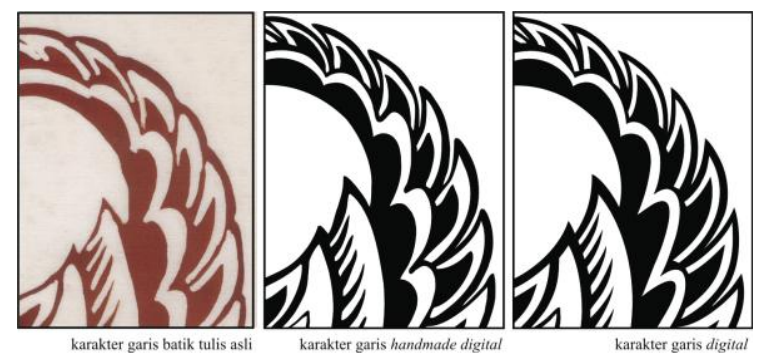

Gambar. 6. Perbandingan karakter garis batik tulis asli, handmade digital, dan digital

Hasil goresan batik tulis asli terlihat sangat berkarakter handmade dengan bentuk garis yang kurang rapi, dan tidak tegas. Bentuk garis seringkali tidak konsisten ketebalannya, terdapat bagianbagian yang menipis bahkan menghilang akibat proses peluruhan lilin (malam) pada pewarnaannya. Hasil tracing atau penjiplakan batik ke dalam format digital kemudian disempurnakan bentuknya. Pada gambar kedua di atas, karakter handmade masih diperlihatkan dengan ciriciri kurang rapi pada bagian tertentu dan pengulangan detil ornamennya dibiarkan tidak benar-benar mirip satu denga lainnya. Kombinasi handmade - digital menghasilkan kesan gambar buatan tangan namun terlihat lebih rapi namun masih terlihat garis natural yang artistik.Bentukbentuk sudutnya tidak terlalu runcing seperti sering terjadi pada hasil goresan mata canting.Lain halnya dengan gambar 
ketiga di atas, dimana karakter digital sangat kuat dengan bentuk garis yang tegas, kaku, dan sangat rapi.

Bentuk dasar typeface yang digunakan mengacu dari huruf serif yaitu huruf yang memiliki kait atau kaki pada ujungujungnya dan merupakan huruf kapital (huruf besar).Huruf yang memiliki serif atau kait pada ujung batang hurufnya secara umum menyiratkan karakter klasik dan relevan dengan konsep penciptaan typeface Garuda Batik. Eksplorasi dan sintesa bentuk huruf dengan motif garuda sangat leluasa diterapkan pada huruf kapital atau huruf besar sehingga jenis undercast tidak tersedia pada font Garuda Batik.

Penciptaan typeface Garuda Batik mengadaptasi salah satu ciri visual motif batik yang pada umumnya terbentuk dari garis kontur dengan gaya dekoratif. Dekoratif adalah sebuah karya seni yang memiliki daya (unsur) (meng)hias yang tinggi dan dominan. (Susanto, 2002: 30) Typefacedekoratif menggunakan teknik sintesis dan deformasi yang mengkombinasikan antara abjad dengan unsur motif garuda. Karakter garis konturnya diadaptasi dari teknik handmade pada batik tulis namun tetap dikombinasikan teknik digital agar terlihat rapi dan legibel sebagai perangkat baca.

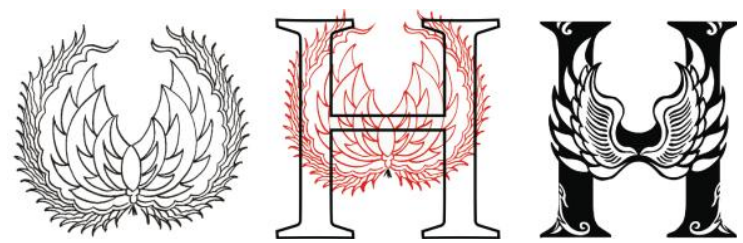

Gambar.7. Sintesis antara motif mirong dengan huruf $\mathrm{H}$

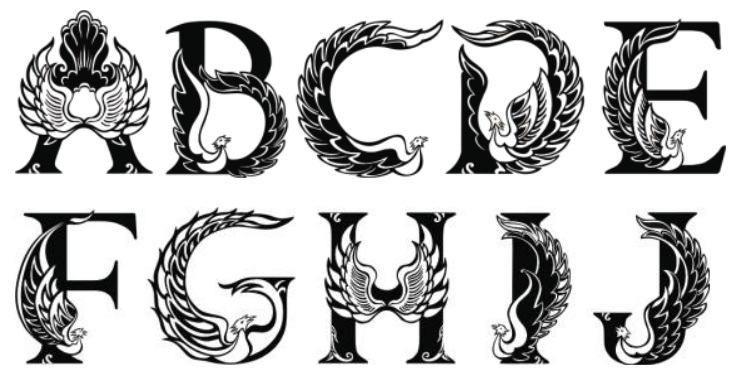

Gambar.8. Beberapa typeface Garuda Batik

Suatu huruf yang typeface-nya dekoratif dan rumit akan lebih legibel diterapkan untuk teks judul atau heading (huruf awal pada paragraf), namun menjadi kurang legibel ketika digunakan sebagai body text. Sebagai perangkat baca, rupa huruf Garuda Batik yang dekoratif dan memuat detail motif garuda akan terlihat rumit dan ilegible jika penggunaannya sebagai bodytext. Typeface Garuda Batik akan terlihat legible untuk diterapkan sebagai heading yang disebut Display Initials.

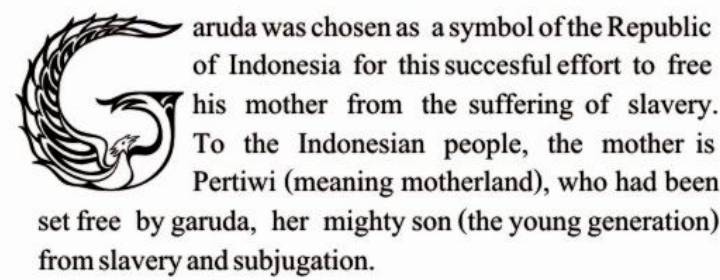

Gambar.9. Contoh penerapan typeface G sebagai Display Initial

Tingkat readibility mengacu pada kemudahan untuk dibaca dan diikuti. Hal ini sangat dipengaruhi oleh cara desainer menempatkan secara fisik dari huruf-huruf tersebut dalam kaitannya antara satu dengan yang lain. Penempatan tersebut dapat mendukung atau justru mengurangi keterbacaan dari sebuah desain secara keseluruhanAplikasi typeface Garuda Batik pada sebuah desain dapat leluasa digunakan untuk perangkat baca sebagai Display initials maupun as an image, di 
mana tampilannya dapat sekaligus difungsikan sebagai ilustrasi. Namun demikian tidak menutup kemungkinan untuk digunakan sebagai headline, judul atau penulisan kata-kata pendek sejauh readibility-nya terpenuhi.

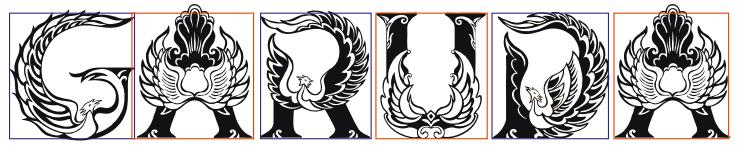

Gambar.10. Contoh spasi typeface Garuda Batik

Peranan Typeface Garuda Batik sebagai salah satu duta budaya bangsa menjadi lebih optimal ketika mendapatkan pengakuan baik dari masyarakat Indonesia sendiri maupun

dunia internasional.Pesatnya perkembangan berbagai jenis media terkini menjadi sarana yang sangat efektif dan efisien untuk menjangkau komunikasi global.Typeface Garuda Batik disajikan dalam format yang aplikatif untuk media cetak maupun media digital 2D dan 3D. Diantaranya sebagai ilustrasi pada $t$-shirt, poster, hingga font (digital) aplikasi MS Word dan Puzzle Game Garuda Batik.Tujuan penggunaan media ini tentunya untuk menjangkau masyarakat modern yang melekat pada perkembangan trend dan berbagai jenis gadget.

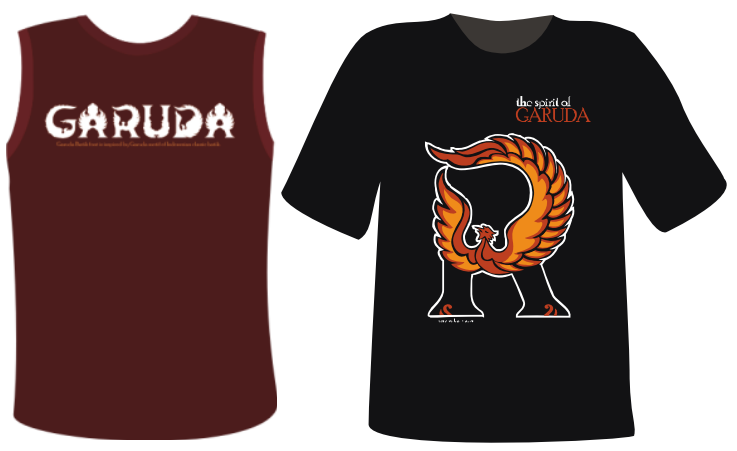

Gambar.11. Aplikasi Typeface Garuda Batik pada baju dan t-shirt

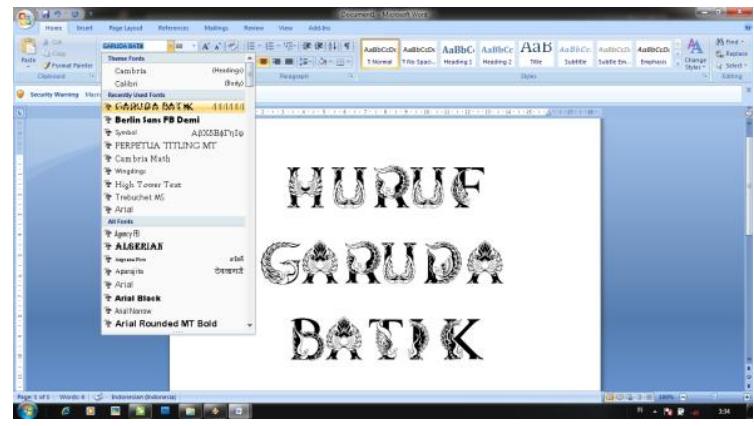

Gambar.12. Aplikasi Font Garuda batik pada software MS Word

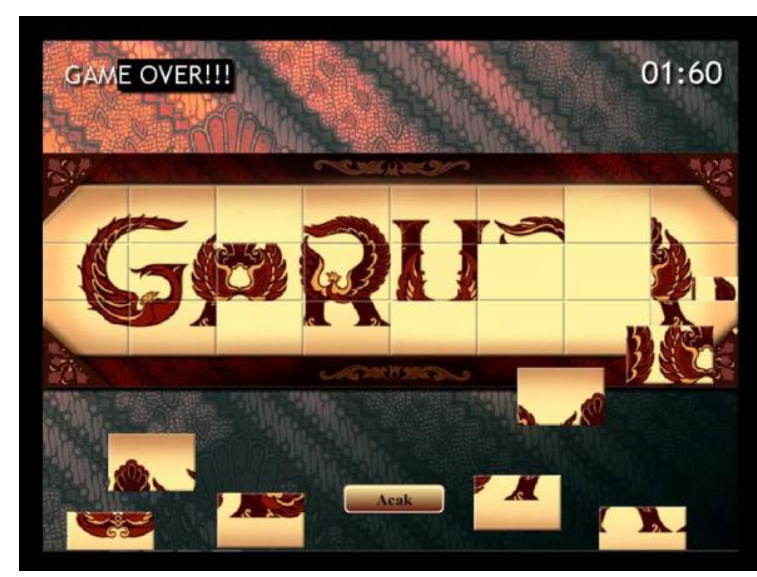

Gambar.13. Aplikasi typeface Garuda Batik pada puzzle game.

\section{PENUTUP}

Typeface Garuda Batik telah berhasil diterapkan secara fleksibel dan adaptif di berbagai media, penentuan teknik dan gaya visual menjadi solusi tepat untuk mengkomunikasikan nilai-nilai luhur motif Garuda kepada masyarakat modern. Karya tipografi ini menjadi sebuah alternatif solusi konkrit yang melengkapi upaya pelestarian dan promosi ragam budaya khususnya batik Indonesia yang sudah dilakukan di bidang fashion.Pada akhirnya typeface Garuda Batik menjadi salah satu karya disain komunikasi visual yang berwawasan kebangsaan dengan 
mengusung tema budaya sekaligus menggugah semangat nasionalis.Penciptaan ini diharapkan melengkapi karya-karya serupa yang pernah ada serta memicu gagasan-gagasan baru untuk mengeksplorasi tipografi dengan mengangkat unsur-unsur budaya Nusantara lainnya yang masih belum terekspos.Eksistensi typeface Garuda Batik menjadi sebuah indeks (jejak) khususnya bagi peminat eksplorasi tipografi untuk mengenal keindahan motif batik klasik garuda beserta makna kearifan lokal budaya Jawa yang melekat padanya. Dengan kata lain, typeface Garuda Batik layak dipercaya sebagai salahsatu duta budaya bangsa Indonesia di kancah internasional.

\section{DAFTAR PUSTAKA}

1. Berryman, Gregg. (1979), Notes on Graphic Design and Visual Communication, William Kaufmann, Inc. ,California.

2. Craig, James. (1990). Basic Typography A Design Manual, Watson-Guptill Publications, New York.

3. Hutajulu, Rina. (2008) "Lihat, Baca, dan Rasakan" Concept.

4. Kusrianto, Adi. (2007), Pengantar Disain Komunikasi Visual, Penerbit Andi, Yogyakarta,.

5. Nursaiman, Dodi. (Agustus 2009), "Bermimpi Menciptakan Typography Directory of Indonesia" Versus

6. Rabinowitz, Tova. (2006), Exploring Typography, Thomson/Delmar Learning, USA,

7. Scheder, George, (1994). Perihal Cetak Mencetak, Penerbit Kanisius, Yogyakarta,.

8. Sihombing, Riama Maslam. (April 2009), "Masalah Tipografi di Pendidikan Indonesia" Versus

9. Susanto, Sewan. (1980), Seni Kerajinan Batik Indonesia, Balai Penelitian Batik dan Kerajinan, Yogyakarta.
10.Susanto, Mikke. (2002). Diksi Rupa, Kumpulan Istilah Seni Rupa, Kanisius, Yogyakarta.

11. Sudjiman, Panuti \& Aart van Zoest. (1992), Serba-serbi Semiotika, PT Gramedia Pustaka Utama, Jakarta.

12. Unesco. (1965), The Art of Writing, Paris, Druck- und Verlagshaus F. W. Wesel BadenBaden, Federal Republic of Germany.

13. Widodo, Suryo Tri, dalam Suwarno Wisetrotomo. (2008), Landskap Tradisi, Praksis Kriya, dan Desain, cetakan kedua, BP ISI Yogyakarta, Yogyakarta.

14. http: $\backslash \backslash$ www.dafont.com/theme.php?cat=20 6. Nopember 2009.

15.http: \\ www.vector_logo.blogspot.com. Juni 2010

\section{BIODATA}

Natalia Hasti Lumenta, M.Sn ( inta )

Lahir di Yogyakarta 11 Desember 1974.

Studi S1 DKV ISI Yogyakarta tahun 1993-1999

Studi S2 Pasca Sarjana Institut seni Indonesia minat utama Penciptaan Desain Komunikasi Visual, tahun 2008 -2010, lulus perdikat Cumlaude.

Sejak lulus S1 langsung bekerja di PT. Agatha Visi Pratama Yogyakarta sebagai desainer grafis, dan pernah sebagai manajer di CV. Point Communication. Sejak tahun 2001 menjadi pengajar matakuliah Tipografi, DKV 1, DKV 2, DKV 3 dan DKV 4 di Akademi Seni Rupa dan Disain Modern School of Design (ASRD MSD) Yogyakarta hingga sekarang. Menjabat sebagai Ketua Program Studi DKV di ASRD MSD periode 2012-2016.

Pernah mengikuti pameran karya poster ILM, gambar bentuk, dan tipografi di lingkungan kampus ASRD MSD, Pascasarjana ISI Yogyakarta, Penerbit Kanisius Yogyakarta, dan Museum Garuda Cangkringan Sleman (tahun 2007-2011).

Menjadi salah satu penulis buku Aksaraaksara Nusantara dengan judul “Keberlangsungan Aksara Nusantara melalui Digitalisasi Tipografi" pada tahun 2010.

Karya thesis "Penciptaan Typeface Garuda Batik sebagai karya Desain Komunikasi Visual bertema kebangsaan". 